\title{
Human Nature: Justice, Efficiency and Culture
}

\author{
Rahul Gupta Choudhury
}

\begin{abstract}
Contrary to expectations of free market theory, people often do not behave as economic agents attempting to maximize their self-interests. It is being argued that choices are very often influenced by moral ideals. This makes the situation more complicated as behavioral patterns vary from culture to culture. This is in contrast to the psychological assumptions of man as a Rational Actor, in microeconomic theories. Choices people make in the ultimatum game experiments cannot describe situation of choosing between a particular amount of monetary gain and moral value. Human beings act according to what is most meaningful for an actor - not only economic, but in - ethical, religious, and ideological sense at a given moment.This article mostly deals with the phenomenological account of meaning-formation, and how these meaning-formation processes are dependent on culture.
\end{abstract}

\section{Introduction:}

Justice and efficiency are the two fundamental principles of human behavior. Justice is a moral ideal of human beings which they strive to achieve even in their everyday life situations. According to proponents of free market theory, these same human beings are expected to act as economic agents, trying to maximize their self-interests. So, there is an inherent conflict between the ethical ideal and the economic ideal. In the ultimatum game experiments respondents do not behave as monetarily self-interested agents all the way down. Rather, they act as moral agents thus rejecting offers which are monetarily beneficialto them, but at the same time seems unfair (to them). [Viik, Tonu; (Tallinn University, Estonia); Human Nature or Cultural Constructs:A Phenomenological Account of Justice and Efficiency Conflict; Homo Oeconomicus, 27(4):481-491 (2011)].

Since a large part of this study revolves around phenomenological research, let us have a look as to what exactly it entails. According to definitions and explanations provided by Stanford, phenomenological approach identifies the phenomena - as to how it is perceived by the actors in a given situation. It always tries to illuminate the specific. The purpose is to gain insights and perceptions through inductive, qualitative methods. It is the study of experience from the perspective of the individual and is represented through the perspective of the research participants. This form of research is a paradigm of personal knowledge and subjectivity, and emphasizes the importance of personal perspective and interpretation. It helps usin understanding subjective experiences and provides insight into people's motivations and actions.

Game-Theory:At this point in time let us recapitulate the fundamentals of game theory along with the essence of the relationship between economics and business. Game theory is the study of strategic decision making $-\mathrm{a}$ study of mathematical models of conflict and cooperation between intelligent rational decision-makers. An important part of game theory is the zero-sum game, where one person's gains exactly equal net losses of the other participant(s).John von Neumann, the father of modern game theory, discovered the existence of mixedstrategy equilibria in two-person zero-sum games. It will pertinent to state here that a game consists of a set of players, a set of moves (or strategies) available to those players, and a specification of pay-offs for each combination of strategies. In economics and business, the model depicts competing behavior of interacting agents. This has widespread applications like in auctions, bargaining, fair division, duopolies, oligopolies, social network formation, agent-based computational economics, general equilibrium, mechanism design and voting systems. The model encompasses various branches of economics like experimental, behavioral, information, industrial organization and political economy.

Strategies are known as equilibria in games and "solution concept" is based on what is required by norms of rationality. Nash Equilibrium is a form of non-cooperative games where each set of strategies represent a best response to the other strategies. So, the players have no unilateral incentive to deviate ad their strategy is the best they can do given what others are doing. Payoffs represent utility of individual players and a game is very similar to some particular economic situation.

Efficiency \& Justice: In our discussion on efficiency and justice [Mathis, Klaus; Searching for the Philosophical Foundations of the Economic Analysis of Law; University of Lucerne, Switzerland; Translated by Deborah Shannon (Springer)], we take a look at different goals and possible relations between efficiency and justice. In the discussion on efficiency criteria, which is the traditional concern of welfare economics, we have positive and normative elements. Positive element explains how certain economic policy measuresand economic 
regulatory systems influence a country's economic development. Normative element, which evaluates social states, finds out whether the effects triggered by a particular action are thought to have raised or lowered welfare. This is in consonance with Max Weber's value freedom or value-judgment problem. In Pareto Optimum, a state is reached when one person's position cannot be improved any further except by making another person worse off. So, efficient production is a state where production of one good cannot be increased without having to curtail production of another good. Efficient consumption is when no further mutually beneficial exchanges are possible. Efficient production structure is the optimal coordination of consumption and production.

John Rawls's Theory of Justice attempts to reconcile calculated self-interest with basic rights. Principles of justice are derived from Economic Choice Theory and Rational self-interest. The special situation of choice is characterized by equality and freedom. In later stages, it evolved into not only rational, but reasonable as well. Individuals have the ability to form, verify and rationally pursue a conception of goodness. They also possess a sense of justice. So, their relationship to society's conception of justice is one of responsibility.

As has been discussed earlier, justice and efficiency are two different goals with three possible relations. The first relationship is that of goal harmony, where pursuit of one goal would be beneficial for the other goal (for example, having just institutions). The second one is that of goal neutrality, where the pursuit of one goal has no effect on the achievement of the other. The third relationship, which is the majority, is that of goal conflict. Here, justice and efficiency are substitutable; and up to a certain point are interchangeable and trade-offs may be made. Trade-off, when it is at the Values level, is about how much justice a person or a society is prepared to sacrifice in order to achieve more efficiency.Trade-off, in the production level, is about how much justice must be sacrificed in order to achieve a certain level of efficiency. Types of Justice, which is the fifth book of Aristotle's Nicomachean Ethics, talks of universal justice being the most perfect virtue. This universal justice is the virtue which contains all other virtues.

Overall, justice may be seen as either distributive justice or commutative justice. Distributive justice is the allocation of benefits by the state, where rights are distributed to the people according to their social status and merit. Commutative justice is private transactions where equalization of goods with other goods takes place without distinction of person. In case of voluntary transaction, it is called justice in exchange. In case of involuntary transaction, it is called corrective justice. In the static concept of distributive justice, the following are the six main distribution criteria:

1. To All in Equal Measure - which is about equality of outcome / opportunity

2. To All According to Their Convictions - which is about inner attitudes and values

3. To All According to Their Rank - which is about aristocratic conception of social status

4. To All According to Their Legal Entitlement - which is about law and the rightful due

5. To All According to Their Needs - people's inner motivation to alleviate certain states of deprivation

6. To All According to Their Merit - where endeavor is rewarded with corresponding remuneration Contemporary theories, which are dynamic in nature, advocate institutional structures which enable individuals to do certain things, or to realize life plans, regardless of the exact result of the ultimate income distribution.

Experiments:TonuViik (2011), in his article discusses a few very interesting experiments. Holler and Leroch (2010: 312) reported that in western industrial societies, thousands rejected offers of less than $\$ 20$ out of $\$ 100$. To them, less than $\$ 50$ was unacceptable. They reported that in western industrial societies, the norm was 40$50 \%$. This seemingly irrational choice is difficult to explain. However, Joseph Henrich (2000) offered $26 \%$ to Machiguenga people in Peruvian Amazon area. Only 1 out of 31 rejected. In yet another experiment of similar nature, Frank Marlow (2004) offered 33\% to Hazda tribe in Tanzania. Only 24\% rejected. These experiments clearly prove that culture, in the anthropological sense, determines how people behave as economic agents. We may observe that people in capitalist societies care less about money and more about fairness compared to noncapitalist societies. So, we need to do away with human nature and adhere to cultural relativism position where human behavior and values are dependent on cultures. This is, however, opposed to the Kantian notion of universal concept of justice which is valid for all human beings. Now, economical theory has a double problem: a) people behave ethically instead of maximizing self-interest, \& b) ethical "inclination" is culture-specific feature of his conduct. So, we are faced with the prospect of revising assumptions about nature of acting subjects. At this juncture we supplement this with Adam Smith's philosophical psychology behind the economic theory. Self-interested behavior has its place in everyday life, in market relationships. We need to complement this with the psychology of acting human agent, which is a "deviation" from the expected pattern, and this is dependent on culture.

Moral Philosophy:At this point in our discussion, we need to recall and deliberate on Adam Smith's Moral Philosophy. In the 'Newtonian Method' of 'system of natural liberty', the economy is a harmonious order and a 
systematic explanation of the world in terms of the fewest possible cardinal principles. Individuals acting for their own profit motive simultaneously contribute, as if by an invisible hand, to producing the greatest possible social wealth. In Theory of Ethics, self-interest is founded on self-love and personal responsibility. It is this selfinterested human endeavor that drives economic growth. However, too much self-interest (egoism, selfishness) is as morally objectionable as too little (laziness, refusal to work). The forces that control self-interest is sympathy (or fellow-feeling) and the concept of impartial spectator. Sympathy is an enabler and is a prerequisite for any kind of moral evaluation and judgment (it is a weaker passion than self-love). In impartial spectator, we are morally qualifying both our own as well as other people's conduct. This spectator is assumed to judge our deeds and feelings from a certain distance. There are three virtues which act as general rules for an impartial spectator. They are: Prudence to multiply one's own happiness, and Justice and Beneficence to multiply the happiness of others. The following quote from The Invisible Hand is illuminating: 'it is not from the benevolence of the butcher, the brewer, or the baker, that we expect our dinner, but from their regard to their own interest. We address ourselves, not to their humanity but to their self-love, and never talk to them ofour own necessities but of their advantages.'

TonuViik (2011) in his discussion on cultural impact of the behavior of the rational actor brings in Adam Smith with his conceptualization of human empathetic faculty for sympathy as a mechanism of cultural regulation of human behavior. The impartial spectator perspective, which is derived from sympathy, evaluates and control and restructure our behavior. Cultural regulator gives us similar features from some common platform of experience. This comes in degrees and is stronger to closer connections. Impartial spectator is uniform irrespective of class, society and country. Ken Binmore, in his Theory of Evolutionary Ethics, claims that there is no inconsistency between self-interested and culturally influenced moral behavior. Edward Rubin, through phenomenology, provides an alternative explanation of a more realistic psychological model. The question raised is: is Economics based on a kind of psychology? Rubin (1998: 1705) answers in the affirmative. He expostulates a theory of the way the human mind functions and asserts that any model on how human beings behave under specified conditions has to be based on psychology. The weaker version of the Rational Actor Theory in Economics talks of maximizing ability to achieve goals. The stronger version postulates goal as material self-interests.

The Rational Actor Theory, according to Rubin, has three premises:

1. Methodological Individualism - human beings are autonomous active forces of the social world.This is contrary to theories of general will.

2. Instrumental Rationality - social actors try (attempt) to achieve their goals in the most effective manner, and that people's preferences can be rank ordered.

3. Utility Maximization - this theory gains in precision if we define goals as being material or monetary only.

Rubin argues that the Rational Actor Theory is inadequate as a view of human psychology as it works only in a limited range of situations. Typical "deviations" include endowment effects, regret, excessive optimism, altruism, self-sacrifice, ideological commitment, cooperation etc. We will recall here that phenomenology defines the boundaries between areas where people will behave rationally and the area they will not. It analyzes meaning formation in the "natural attitude", where "natural attitude" is the mode of being engaged in everyday life.

Meaning Formation:However, how things appear cannot be explained by psychological view of a passive human mind. Perceptions of things are formed by the active process of interpreting inflowing data. It is achieved by means of several types of meaning-bestowing operations which are highly complex in nature - composed of mathematical models or moral ideals. Meaning bestowing activities in his consciousness determines how things and events are construed as good or bad, important or unimportant, friendly or hostile, pleasant or repulsive, just or efficient, etc. Both, Rational Theory and Phenomenology, proceed from the same assumption. Methodological Individualism rejects the view that humans are subjected to collective cultural forces and do not make individual choices in their own minds. Phenomenology points towards the emergence of motifs in the consciousness of the individual, and motifs are derived from meanings. We may now recall the experiments cited earlier, where we discussed the choice between self-gain and concern for fairness. We may conclude with this understanding that it may be termed as a choice only when in the ultimatum gain; the options were properly comprehended and made meaningful for him.

TonuViik (2011), in his article, presents a phenomenological account of meaning formation. He claims that the subject himself is the active agent of meaning formation. Meaning -formation,which is the basis for empirical perception, is actually different types of synthesis of contents of consciousness. Consciousness accomplishes this effect of sameness in perception of different aspects of object around temporal and spatial substantiality. Substantiality of the object is not empirically perceived, but, applied to empirical data. So, the 
main issue to understand and appreciate is that whenever one experiences something, it is experienced AS something. The same situation is interpreted differently by different people, as it has different meanings. In the earlier part of this discussion, we saw that it becomes a choice only when the deal is meaningful for the respondent. In other words, it means that the deal BECOMES meaningful for the respondent only when he comprehends what the win/lose options mean to him. The outcome maybe not only economical or theoretical, but also moral, ideological, religious etc. From the phenomenological point of view, particular meaning motivate him tomake the choice. It is not the particular sum of money itself versus universal or culturedependent moral ideals. It is not about the objective monetary value, but its meaning. The outcome is dependent on how important a given sum is for the respondent, or how desperate/indifferent he is towards the possible gain. For a student of industrial society, \$20 may not be substantial - but, for a student of underdeveloped society, it may not be so at all. It would be interesting to see the results if the deal was more unfair but more lucrative, like \$ one million out of a hundred. Thus we need to base our psychology o subjectively experienced meanings of the deal, rather than on the objectively measured value of money.

Culture \& Development:This brings us to a discussion on culture and economic development at the aggregate level. In an article (Fukuyama, F.; Culture and Economic Development: Cultural Concerns; International Encyclopedia of the Social and Behavioral Sciences; 2001, Elsevier Science Limited) on cultural concerns in this area, the author defines culture as informal shared values, norms, meanings, and behaviors that characterize human societies. On the other hand, economic development presupposes not just the existence of formal institutions like property rights and a rule of law under which buyers and sellers can exchange goods in the markets, but also certain norms or social values that promote exchange, savings, and investment. Thus there is a cultural dimension to economic behavior. Modern neoclassical economics downplay importance of culture to development. They believe that rational utility-maximizing behavior is invariant across different human societies. Here, we will do well to remember that Robert Solow in his standard economic growth model talks of inputs of labor and capital. Recent "endogenous" growth models however emphasize the role of technology. Max Weber observed that output can be increased by raising piece-rate. However, raising rates has an opposite effect on certain peasant societies, as they value leisure over accumulation. With the advent of Protestantism, shift in cultural values took place before the emergence of the modern economic world. Valuing of work for its own sake rather than its results is contrary to the philosophy that one should acquire only as much wealth as is required to live well. It was believed that culture was the main obstacle in development in China, Japan, and other Confucian societies in East Asia. However, it has concluded later that the obstacles to development are politics and inappropriate institutions, and not any specific cultural factor. Centrality of kinship as an organizing principle in Chinese society is a reality, where businesses have been and continue to be family centered. So, many believed that "lack of achievement orientation" is an obstacle to development. The criticism of ethnocentrism is that cultural factors are very difficult to measure and to disentangle from other kind of variables. There is now a revival of cultural interpretations through New Institutional Economics, which says "path dependent factors" shape economic behavior. In supporting this, they cite the example of 'Asian Miracle', East European countries and Soviet successor states. Cultural factors affect economic behavior in the following ways:

1. Impact on organization ad production

2. Attitude towards consumption and work

3. Ability to create and manage institutions

4. Creation of social networks

Social Capital is a source of wealth and may be defined as norms and values shared among a group of people that promote cooperation and trust among them. This results in a comparison ofpropensity forcivil association versus 'amoral familism'. Flow of information is what is most important, as has been exemplified by Micro lending projects in the developing world. However, it is still difficult to incorporate social capital into econometric models because of the absence of a good metric.

Cultural Impact - Phenomenology: Now, let us have a look at cultural impact from the phenomenological point of view. The meaning of the deal is dependent on collectively held idealities which may be cultural, religious, ideological, or ethical ideals. This leads us to the questions: how do these ideals influence the choice of the respondent and the proposer? How do they participate in forming the meaning of the deal for them? What is the agent of culture within our minds that performs the function similar to Smith's impartial spectator? Individual choices tend to be stereotypical. Consequently, our individual meaning-formation processes bear collective similarities. Husserl's phenomenological theory has the conception of life-world which, according to him, is the world of "valid realities" engaged with "natural attitude". Valid realities are primarily material things, but also encompass ideal things which are true, existing, or valuable. This will include religious beliefs, common sense knowledge, scientific theories, famous artworks, etc. Life-world is not the world of physical 
objectivities around us. It is the world as it is experienced by human beings. Ideal things possess specific "ideal objectivity" and are perceived by a certain range of subjects as EXISTING.

These idealities may be difficult to discover from the external point of view. For example, Euclid's theories for mathematicians and non-mathematicians, or similar concepts like God, nation, homeland, communism or democracy. Usually those objects are real for an individual that he sees other subjects experiencing as real (inter-subjectively constituted validity - objectivity of ideal subjects). As a result, intersubjective harmony occurs, which is "normal" for a community of subjects. Dan Zahavi (2001: 100) thinks that one type of intersubjective constitution of reality operates at the level of the creation of reality. Formation of judgments, self-apprehension, evaluation, and interpretation of the world takes place with sense being provided by others and guided by a linguistically articulated pre-understanding. Understanding the world and its relationship with the subject is actually handed down through linguistic conventionality. The result is that individual experience is always already "communalized". Thus there is a cultural regulator of human behavior which is an internalizedfeature of consciousness. This is similar to Smith's invisible spectator, which further adds that as a result of interaction with others, a certain " community of subjects.So, the idealities collectively held as valid in the particular community are applied by the subject and communalization of experience occurs. These collective idealities define the respondent as well as the proponent as they experience the offer. This definition is not just about the contents, but also about the emotional significance which categorize possible choices as an economical, moral, or religious decision, etc.

Thus, the meaning of the deal is derived from applying the meanings, which is again derived from collectively held realities. This is the phenomenological account of culturally influenced, yet, individually performed meaning formation. On one side of the scale is the perspective of monetary gain; on the other side of the scale are "ideal things". The subject creates a unified meaning which is most meaningful to what he does. Unified meaning includes weighing of alternatives; meaning formation includes multitude of evaluations of varying possibilities - himself, other subjects, his life in general, his social surroundings etc. In the concept of instrumental rationality, we have seen that people rank order their preferences, but they do not do so by counting or measuring benefits. He chooses what is most meaningful for him, and evaluates the deal from all possibleperspectives. Thus phenomenological account agrees with rational actor theory, especially the methodological individualism and behavioral premise aspects of instrumental rationality. So, choice is motivated not by self-interest, but by the desire for meaning. Sometimes the most meaningful aspect of a person's life would be to maximize material well-being of themselves and their children; in many other situations, it could be to serve God, serve one's country, to become famous, to experience adventure etc. The objective value of money has only an indirect impact, as money matters because it means something for the subject. The common denominator for self-gain possibilities versus other options of choice is subjectively experienced meaning. For the subject, it is not money and moral virtues on two sides of the scale, but these two and many other alternative meanings. The decision depends on which is most meaningful at a given point in time. People seek money because money contributes to the way they want to view their life. At any given moment a large variety of alternative idealities are used for making sense of a particular situation. This makes it possible for a human being to arrive at unexpected choices from the various alternative meanings. To quote Viik: "Even pathologically self-centered people will often exchange material resources for power or fame, while normal people will exchange material resources for aesthetic or lifestyle benefits that are more meaningful for them". These exchanges simply make sense to them, and the sense is what matters.

Comparison of Two Communities:Having made sense of how people make decisions based on the meaning or sense it makes to them, let us proceed a little further to enlarge the picture to the macro level. For a considerable amount of time, arguments were taking place on whether or how, if at all, there is a relationship between culture and economic development. In an article [Frederking, Loretta Conklin; Is there an endogenous relationship between culture and economic development? Journal of Economic Behavior and Organization; Vol. 48 (2002), 105-126], the author garners evidence from two communities which suggest divergent paths of economic development. One integrates culture in economic activities, while the other does not. They are: 1) The Punjabis in Southall, London; and 2) The Gujaratis in Wembley, London. Research suggests that the debate should shift towards studying variation in the endogenous relationship rather than assuming the presence or absence of the connection. The study demonstrates that an important component of the relationship is the various mechanisms that define the relationship between culture and economic activities (development).

The author finds that in the Punjabi community, the geographic separation has been dealt with mechanisms preserving the integration of culture and economic activities. In Gujarati community, there has been an institutionalizing of culture, a mechanism which limits the role of culture in development. In Wembley, culture is of limited relevance and is used as a temporary foundation to cultivate business in the short run, and is often a springboard for expansion toother areas.Southall, on the other hand, is characterized by captured Punjabi consumption and is unable to develop appeal beyond the immediate neighborhood. It is a localized cultural 
population which displayed strong signs of economic stagnation. Punjabis cultivate their cultural attachments which is advantageous in the short run. However, in the long run, it prevents accumulation of profit. The geographic separation of Southall is not stable as cultural identification is not sustained by the individual's preferences. Gujaratis are looking beyond long run economic development by institutionalizing their culture. This defines individual experience of culture, but allows for its sustainability in a non-Indian environment. So, evidence shows that it is important to study culture in order to understand development. However, it cannot be concluded that culture is relevant during the process of development.

Contrary to current theoretical resurrection of culture, culture's characteristics do not determine culture. The impact is determined by the way culture is organized. Theoretically, there is a much greater possibility of generalization when mechanisms of organization are the focus of explanation, rather than specific cultural values. Practically, evidence suggests, that politically charged and empirically suspect activity of measuring and comparing development potential behind different cultural values, is irrelevant. Cultures can persist without negative effects on development, and in this way, economic progress is possible and can be reconciled with cultural diversity.

Wealth Maximization:While on the subject of development, it may not be out of place to have a short discussion on Richard Posner's Theory of Wealth Maximization. Transaction, or some other change in the use or the ownership of resources, is advantageous if it increases social wealth. Where transaction costs are prohibitive, the market should be simulated by means of state compulsion. Richard Posner says: "The wealthmaximization principle encourages and rewards the traditional virtues and capacities associated with economic process. The capacities (such as intelligence) promote the efficiency with which resources can be employed; the virtues (such as honesty, and altruism in its proper place) by reducing market transaction costs do the same". He coined the term "Moral Monstrousness", which is derived from utility theory and the idea that pleasure is not finite. Efficiency stands for productivity or the performance of the company. An increase in efficiency normally means an increase in economic output without regard for income distribution ('economic output' can be replaced by 'wealth'). Efficiency is an instrument for achieving other social goals. In the construct of Justice in Exchange and Efficiency, Aristotle says that exchange of goods is a question of price justice. The just price (iustumpretium) should be determined in such a way that the payment and what is rendered in return are in equilibrium. This means that nobody is better or worse off after the trade.

Economic theory questions the validity of this equality principle: those involved benefit from the trade and are better off than they were before. They experience a utility gain. However, we must remember that different valuations of goods are based on people's differing preferences. Goods are traded as long as both parties can benefit, or, if at least one stands to benefit without making the other worse off. So, societies utility increases, which is termed as Pareto-superior change. Social utility can be increased through trade until efficient consumption has been achieved. This, however, assumes the model of perfect competition; whereas, in reality, business firms try to stifle competition through monopolies or cartels. The solution lies in state control, price control, state regulation etc. In the concept of Corrective Justice and Efficiency, efficiency is certainly desirable as long as it does not clash with corrective justice. Hence, legal rules should primarily be just, and need only be efficient as a secondary concern.

Calabresi is of the opinion that it is always easier to say what is unjust. Society should examine whether liability rules are efficient first, and those rules which are deemed unjust should be eliminated in the next step. The unanswered question is whether any of the efficient legal rules would also satisfy society's conception of justice. The relationship of Distributive justice and Efficiency is one of antagonism. This is the greatest socioeconomic goal conflict because efficiency follows the principle of insatiability of needs. Another reason is that redistribution is bound up with efficiency losses. Generally, the factors for leakage losses are:

1) Administrative costs

2) Negative effect on work incentives

3) Negative effect on saving and investment

4) Negative effect on people's values

Relation between efficiency and distributive justice need not always be a trade-off. On the contrary, in many areas there is a positive correlation. For example, in the education system, highly skilled workers are equalizing starting opportunities. According to Posner, civil courts should be committed to the efficiency principle, whilst the public sector could concern itself with distributive justice. The modern system is subdivided into the following two sections:

1) Regulate the private exchange of goods and services, which is guided by the efficiency goal

2) Dealing with tax and social law, the efficiency goal should be counterbalanced by pursuing the goal of distributive justice.

The criticism of this thought process is that allocation and distribution are indivisibly linked to one another. It is not possible to have efficient production on the one hand and just distribution on the other. Taxes and transfers 
also have an influence on work incentives and the use of production factors. Hence, redistribution via the state administrative apparatus is not necessarily always more efficient than redistribution through regulation of the private sector.

\section{References:}

[1]. Holler, M.J. and Leroch M. (2010), Efficiency and Justice Revisited, European Journal of Political Economy 26(3): 311-319.

[2]. Husserl, E. (1989), Ideas Pertaining to a Pure Phenomenology and to a Phenomenological Philosophy, Studies in the Phenomenology of Constitution, Dordrecht: Kluwer Academic Publishers.

[3]. Rubin, E.L. (2001), Public Choice, Phenomenology, and the Meaning of the Modern State: Keep the Bathwater but Throw out that Baby, Cornell Law Review 87: 309-361.

[4]. Steinbock, A.J. (1995), Home and Beyond: Generative Phenomenology after Husserl, Evanston, Illinois, Northwestern University Press.

[5]. Aristotle, The Nichomachean Ethics, translation by William David Ross (Oxford, 1908; cited as NE, book. Chapter, section).

[6]. Arrow, Kenneth J., Social Choices and Individual Values (2nd edn., New York,1963).

[7]. Baumol, William J., Economic Theory and Operations Analysis (3rd edn., London, 1972).

[8]. Coleman, Jules L., 'The Grounds of Welfare', in: The Yale Law Journal, Vol. 112 (2003), pp. 1511 ff. (cited as: 'Grounds').

[9]. Gintis, Herbert er al. (eds.), Moral Sentiments and Material Interests: The Foundation of Cooperation in Economic Life (Cambridge, 2005).

[10]. Viik, Tonu; (Tallinn University, Estonia); Human Nature or Cultural Constructs: A Phenomenological Account of Justice and Efficiency Conflict; Homo Oeconomicus, 27(4):481-491 (2011).

[11]. Mathis, Klaus; Searching for the Philosophical Foundations of the Economic Analysis of Law; University of Lucerne, Switzerland; Translated by Deborah Shannon (Springer).

[12]. Fukuyama, F.; Culture and Economic Development: Cultural Concerns; International Encyclopedia of the Social and Behavioral Sciences; 2001, Elsevier Science Limited.

[13]. Frederking, Loretta Conklin; Is there an endogenous relationship between culture and economic development? Journal of Economic Behavior and Organization; Vol. 48 (2002), 105-126.

Author: Prof. Rahul Gupta Choudhury is an MBA from IIM(L), India. He did his graduation in B.E. (Chem.) He was a Fulbright scholar to Carnegie Mellon University, USA. He has 15years experience in industry and is teaching in reputed business schools in India for the last nine years. He is pursuing his Ph.D. and is in the final stages of his thesis. He has published ten research papers and articles in Indian and International reputed journals. He has also participated and presented in conferences and Doctoral Colloquiums in Melbourne (Australia), Hyderabad, Bangalore, and IIM(Ahmedabad) - organized by American Marketing Association and Academy of Marketing Science (USA). 